\title{
Methodologies for hydraulic hazard mapping in alluvial fan areas
}

\author{
LUCA MILANESI, MARCO PILOTTI, ROBERTO RANZI \& GIULIA VALERIO \\ Department of Civil Engineering, Architecture, Land and Environment and of Mathematics - DICATAM - Università \\ degli Studi di Brescia, Via Branze, 43-25123 Brescia, Italy \\ luca.milanesi@unibs.it
}

\begin{abstract}
Hydraulic hazards in alluvial fan areas are mainly related to torrential floods and debris flows. These processes are characterized by their fast time evolution and relevant sediment load. Rational approaches for the estimation of hazard levels in flood-prone areas make use of the maps of depth and velocity, which are provided by numerical simulations of the event. This paper focuses on national regulations regarding quantitative debris-flow hazard mapping and compares them to a simple conceptual model for the quantification of the hazard levels on the basis of human stability in a flood. In particular, the proposed method takes into account, in a conceptual fashion, both the local slope and the density of the fluid, that are crucial aspects affecting stability for processes in mountain environments. Physically-based hazard criteria provide more comprehensible and objective maps, increasing awareness among stakeholders and providing more acceptable constraints for land planning.
\end{abstract}

Key words debris flows; hazard mapping; human stability; torrential floods

\section{INTRODUCTION}

Debris flows are rapid mass movements, characterized by strong granulometric heterogeneity, typical of steep mountain basins. These processes may be triggered by soil saturation on steep slopes hit by heavy rains, with further propagation in streams. The deposition areas, usually characterized by separation of the fluid and the solid phase, are located on alluvial fans, which are themselves clear evidence of such geomorphic events. The growing anthropization of such affected areas in the European Alps, in recent decades, suggests the need for a careful assessment of the potential consequences of these hydraulic events. Because of their impulsive and violent behaviour not only damages to properties, but particularly human safety should be considered as a measure of the hazard.

Although national regulations consider both qualitative and quantitative hazard zoning approaches, the latter, based on the outputs of numerical modelling, allow improvement of the results of hazard assessment procedures (Quan Luna et al. 2012) although several uncertainty elements remain (Mazzoleni et al. 2013). For instance, the definition of the return period of the debris flow event refers to the liquid discharge only, disregarding the effect of sediment availability on the overall volume and concentration. A crucial point for reliable debris flow simulation (Arattano et al. 2006) is the definition of the rheological properties of the mixture, especially if no historical data are available for back-analysis (Boniello et al. 2010). The calibration of the constitutive laws through rheometric tests might be strongly limited by coarse sediments (Cussot et al. 1998) and it would be advisable to take into account the two-phase nature of the flow (Iverson 2003, Armanini et al. 2009). Finally, the reliability of the hazard maps depends on the physical background of the criteria on which they are based. In several cases, these criteria are suggested from experimental and theoretical studies defining stability limits for humans, vehicles and buildings in a flood. Other methods consider flood extent, depth or flow quantities such as the specific energy or the specific force. In general, to support the constraints to land-use planning, the adopted hazard criteria should account for multiple variables on a rational basis.

In this paper, different quantitative criteria were applied to debris flow events in three small Alpine basins. The hazard maps were obtained from the combination of the maximum velocity and depth envelopes with the Austrian, Japanese and Swiss thresholds. Finally, these maps were compared to those obtained by applying a simple conceptual model describing human stability in a flow. This approach is more cautionary than the real-time hazard assessment during flood routing because maximum water depth and velocity in a cell do not necessarily occur simultaneously. 


\section{MAIN REGULATIONS IN THE INTERNATIONAL FRAMEWORK}

\section{Austria}

The Austrian regulation provides different hazard criteria for fluvial floods and torrential processes (Faber 2006). This paper focuses on the latter as they are more representative of debris flows. The subdivision of high hazard areas (red) from lower hazard zones (yellow), is based on the local calculation of the flow specific energy, whose threshold value is arbitrarily set at $1.5 \mathrm{~m}$ (see Fig. 1 where grey-scale levels are used instead of red/yellow colours). The reference return period for hydrological studies is 150 years. However, the hazard assessment based on the value of the flow specific energy, which would correspond to the water depth at a stagnation point, does not allow separate accounting of the effects of velocity (e.g. the drag on an object) and water depth. Moreover it does not consider relevant features such as the density of the fluid and the local slope.

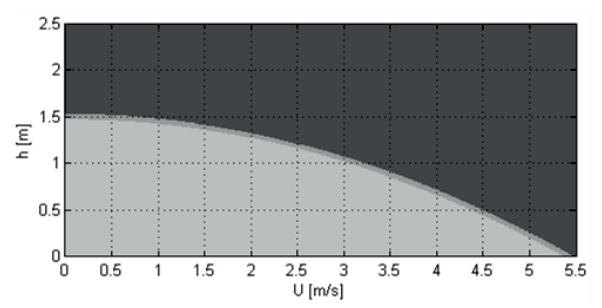

Fig. 1 Austrian hazard mapping criterion for torrential floods. Light grey: low hazard; grey: high hazard.

\section{Switzerland}

The Swiss methodology (BWW, BRP, BUWAL 2008) is commonly used in several regions in the alpine area. The first step for hazard assessment is identification of the intensity of three events of set return period (30, 100 and 300 years) through velocity-depth relationships (Table 1). The thresholds for flood events suggest a clear reference to studies on human and vehicle stability in a flood.

Then, frequency and intensity classes are superimposed on the matrix in Fig. 2 to establish hazard levels in the flood prone areas. The hazard levels are identified by coded colours (in order of growing hazard: yellow, blue and red; yellow-white hatched areas identify residual hazard) and different land-use constraints are associated with each zone according to its hazard level.

Table 1 Intensity classes.

\begin{tabular}{lll}
\hline Intensity & Flooding & Debris deposition \\
\hline High & $h>2 \mathrm{~m}$ or $U h>2 \mathrm{~m}^{2} / \mathrm{s}$ & $d>1 \mathrm{~m}$ and $U>1 \mathrm{~m} / \mathrm{s}$ \\
Medium & $0.5 \mathrm{~m}<h<2 \mathrm{~m}$ or $0.5<U h<2 \mathrm{~m}^{2} / \mathrm{s}$ & $d<1 \mathrm{~m}$ or $U<1 \mathrm{~m} / \mathrm{s}$ \\
Low & $h<0.5 \mathrm{~m}$ or $U h<0.5 \mathrm{~m}^{2} / \mathrm{s}$ & No condition \\
\hline Notes & $h=$ flow depth & $d=$ depth of debris deposition \\
& $U=$ flow velocity & $U=$ debris flow velocity \\
\hline
\end{tabular}

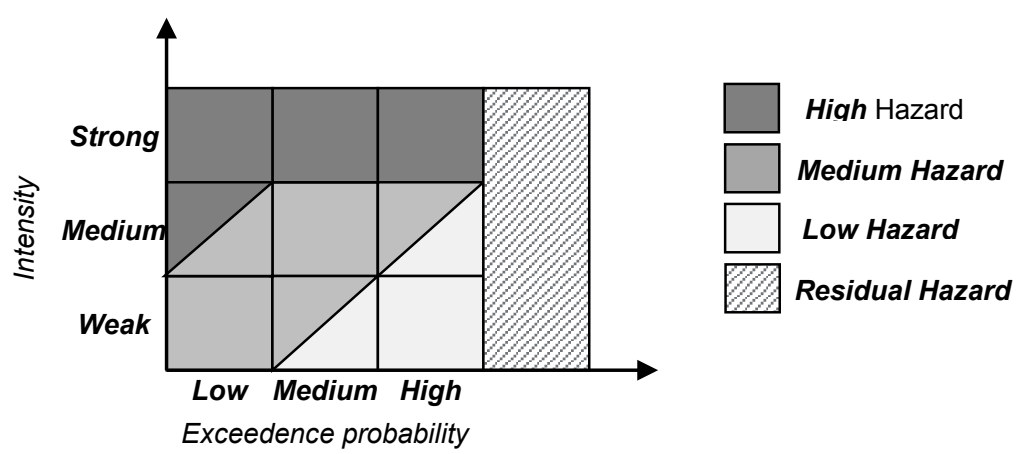

Fig. 2 Matrix for hazard levels assessment in the Swiss methodology where grey scale is adopted instead of the original yellow, blue, red and yellow-white hatched areas. 


\section{Japan}

In Japan, sediment-related hazard assessment is mandatory for debris-flow prone streams with slope greater than $3.5 \%$ below the apex of the alluvial fan. Two hazard classes are identified by the colours yellow and red and associated with different constraints (Uchida et al. 2009). The method is based on assessment of the flow specific force, defined by the dynamic term of the momentum equation in steady state conditions, $F_{\mathrm{d}}\left[\mathrm{N} / \mathrm{m}^{2}\right]$ (equation 1). This term is compared to the characteristic resistance of traditional wooden buildings $P\left[\mathrm{~N} / \mathrm{m}^{2}\right]$ in equation (2) (Mizuno and Terada 2004).

$$
\begin{aligned}
& F_{d}=\rho_{f} U^{2} \\
& P=\frac{35300}{h(5.6-h)}
\end{aligned}
$$

where $\rho_{\mathrm{f}}\left[\mathrm{kg} / \mathrm{m}^{3}\right]$ is the fluid density, $U[\mathrm{~m} / \mathrm{s}]$ the flow velocity and $h[\mathrm{~m}]$ the flow depth. The yellow zones identify the debris-flow prone areas, whilst in the red ones $F_{\mathrm{d}}$ overcomes the building resistance. This model accounts for the variability of the flow force due to the fluid density.

\section{A CONCEPTUAL MODEL FOR HYDRAULIC HAZARD ASSESSMENT}

The extreme fragmentation of the international regulatory framework and the absence of a methodology based on a fully satisfactory rational criterion, suggested the opportunity to propose a conceptual model based on the equilibrium of a human being within a flow (see Fig. 3). In such a model the human being, in standing position orthogonal to the floor, is assumed of height $Y$ [m] and weight $W[\mathrm{~N}]$ and is schematized by two cylinders representing the legs and a cylinder of doubled radius for the torso. The geometric assumptions guarantee that, for a water depth $h$ equal to $Y$, the submerged weight is negligible. This methodology is also coupled with a constraint about drowning in still water, which implies a maximum threshold of water depth of $1.4 \mathrm{~m}$.

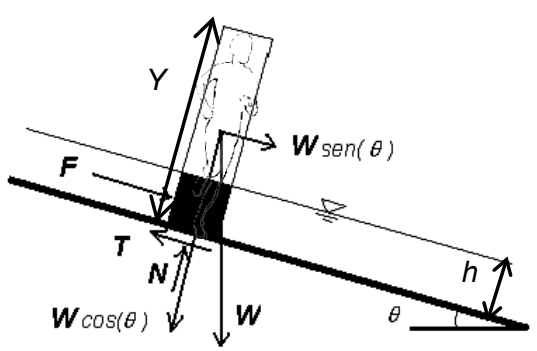

Fig. 3 Scheme of the forces acting on the schematized human body.

The body weight can be split into two components; the stabilizing one is normal to the slope whilst the other is parallel to the slope. The force $F[\mathrm{~N}]$ (Fig. 3), locally exerted by the flow in steady state conditions on the individual, is the equivalent drag force. It depends on the drag coefficient $C_{\mathrm{D}}$ [-], assumed equal to 1 in the range $1000<R e<100000$ for a circular cylinder, the density of the fluid, the mean velocity and the frontal area of the body $A\left[\mathrm{~m}^{2}\right]$, that is in turn a function of $h$ :

$$
F=\frac{1}{2} \rho_{f} C_{D} A U^{2}
$$

The force $N[\mathrm{~N}]$ is the effective buoyancy related to the submerged volume $V_{\text {Sub }}\left[\mathrm{m}^{3}\right]$ :

$$
N=\rho_{f} g V_{\text {Sub }} \cos \vartheta
$$

The friction $T[\mathrm{~N}]$ in a Coulomb approach is calculated by the static friction coefficient $f_{\mathrm{s}}$ [-]:

$$
T=f_{s}(W \cos \vartheta-N)
$$

Assuming $f_{\mathrm{s}}=0.4[-]$, which was experimentally measured by Takahashi et al. (1992) and commonly adopted in the literature (e.g. Jonkman and Penning-Rowsell 2008), it is possible to apply the frictional equilibrium condition (equation 6) and distinguish on the $U-h$ plane (Fig. 4) the areas characterized by high hazard (grey zones) and lower hazard (light grey zones). 


$$
F+W \sin \vartheta \leq f_{s}(W \cos \vartheta-N)
$$

An important element of novelty is that the resulting curves are parametric to the fluid density. Those in Fig. 4 were derived for a debris flow density of $1800 \mathrm{~kg} / \mathrm{m}^{3}$ (Fig. 4(a)), considered a reliable value for the case study presented, and for clear water $\left(1000 \mathrm{~kg} / \mathrm{m}^{3}\right.$, Fig. 4(b)). In the first case, the drag force is the limiting condition with respect to the drowning criterion, while in case of water the drowning threshold is shown in the diagram.

(a)

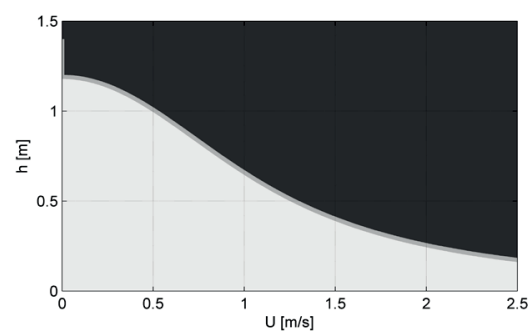

(b)

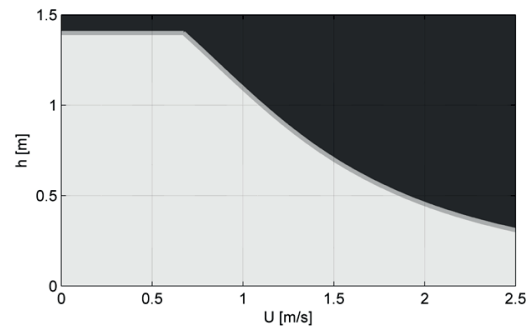

Fig. 4 Hydraulic hazard criterion based on translational equilibrium and drowning limit for an individual run over by a debris flow (a) or by water flow (b); individual mass $71.5 \mathrm{~kg}$ and height $Y=1.7 \mathrm{~m}$. Here $\vartheta$ $=0$.

\section{HYDRAULIC HAZARD MAPPING IN SOME ALPINE BASINS}

To assess the sensitivity of the zoning procedure to the adopted criterion, the described methods were applied to three debris-flow events in small Alpine basins (Table 2) characterized by a 100-year return period for liquid discharge. The hazard maps (Fig. 5) were based on the results of numerical simulations previously performed by the authors with the numerical code FLO-2D (O'Brien et al. 1993) on a 5-m square mesh DEM. For the definition of the mix hydrograph, the liquid hydrograph was coupled with the potential volume of sediment, as evaluated from geological studies. The estimated peak density was $1800 \mathrm{~kg} / \mathrm{m}^{3}$. Because of the absence of historical events for model calibration, seven iso-probable scenarios were produced for each basin with literature rheological data (O'Brien and Julien 1988). The envelope maps of maximum depth and velocity, that in this case are the basis for hazard zoning, were obtained by averaging the outputs of this set of simulations. As the numerical model does not reproduce the mobile bed and the separation of the liquid phase from the solid one, the Swiss method was applied using the envelope of maximum flow depth.

\section{DISCUSSION AND CONCLUSIONS}

Figure 6 shows the percentage of high hazard areas according to each criterion. It is clear that the Japanese criterion provides the lowest safety factor because its curve is calibrated on building resistance. Although quite cautionary with high velocities, it seems poorly reliable in the field of high depths and low velocities. The discrepancies between the European methods look smaller, although the Austrian model appears slightly more cautionary. In these cases the similarity between the Austrian and Swiss maps may be justified by the absence of relevant water depths. Indeed, the

Table 2 Main parameters of the basins and of the simulated events.

\begin{tabular}{llll}
\hline & Basin 1 & Basin 2 & Basin 3 \\
\hline Area $\left[\mathrm{km}^{2}\right]$ & 2.3 & 1.9 & 12.3 \\
Mean slope $[\mathrm{m} / \mathrm{m}]$ & 0.525 & 0.371 & 0.595 \\
Runoff time $[\mathrm{h}]$ & 0.47 & 0.48 & 1.1 \\
Sediment volume $\left[\mathrm{m}^{3}\right]$ & 22000 & 10000 & 45000 \\
Peak concentration $\left[\mathrm{m}^{3} / \mathrm{m}^{3}\right]$ & 0.58 & 0.53 & 0.54 \\
Peak liquid discharge $\left[\mathrm{m}^{3} / \mathrm{s}\right]$ & 11 & 9 & 38 \\
Peak overall discharge $\left[\mathrm{m}^{3} / \mathrm{s}\right]$ & 111 & 50 & 178 \\
Event duration $[\mathrm{h}]$ & 0.83 & 0.72 & 0.9 \\
\hline
\end{tabular}


(a)

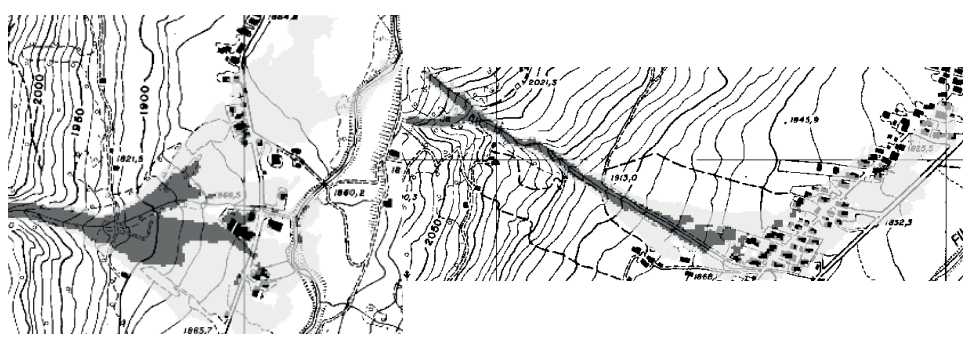

(b)
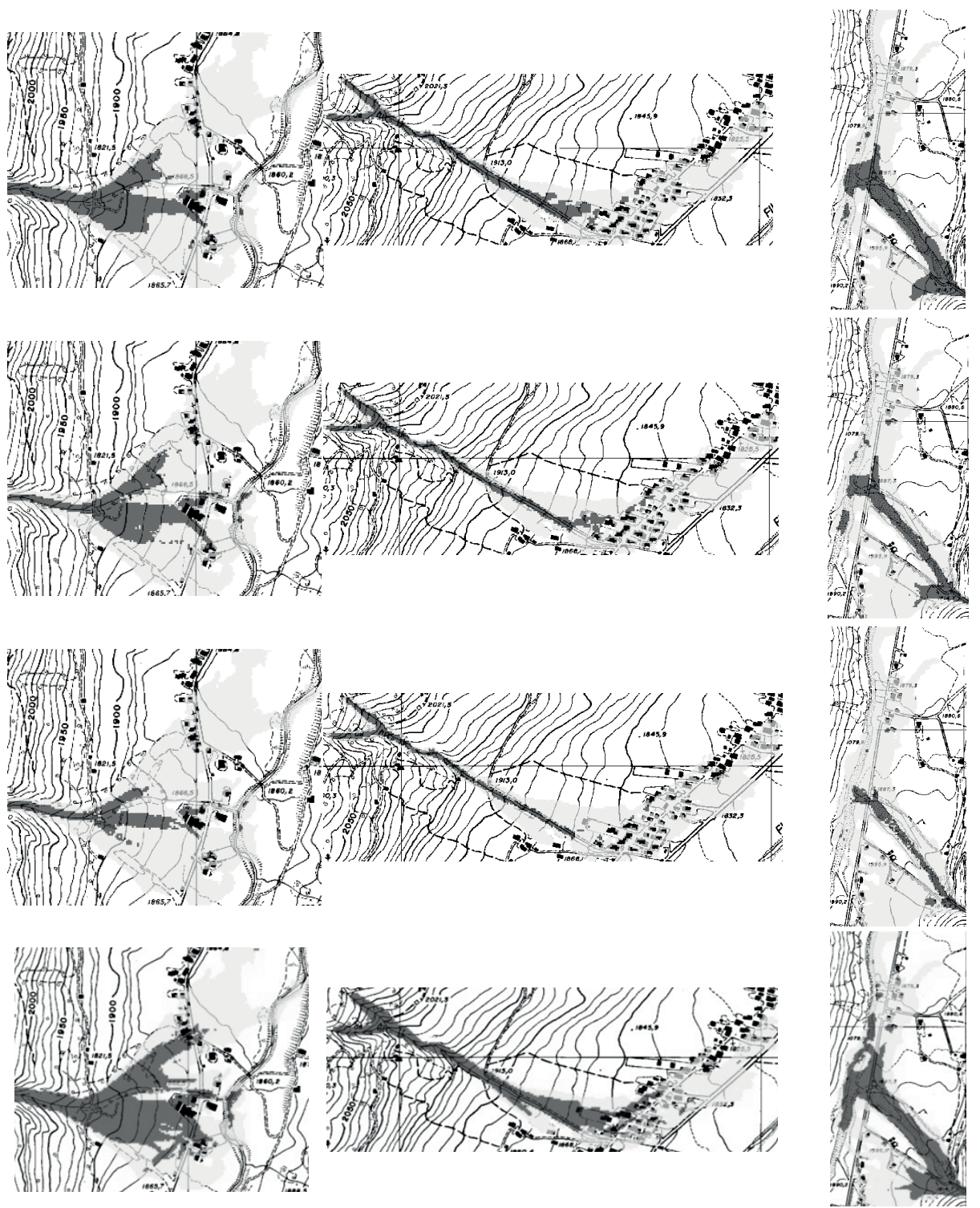

Fig. 5 Hazard criteria according to the Austrian (A), Swiss (B, just T $=100$ year), Japanese (C) and human stability (D) methods. From left: basins 1, 2 and 3. Unscaled. Grey: high hazard; Light grey: medium hazard.

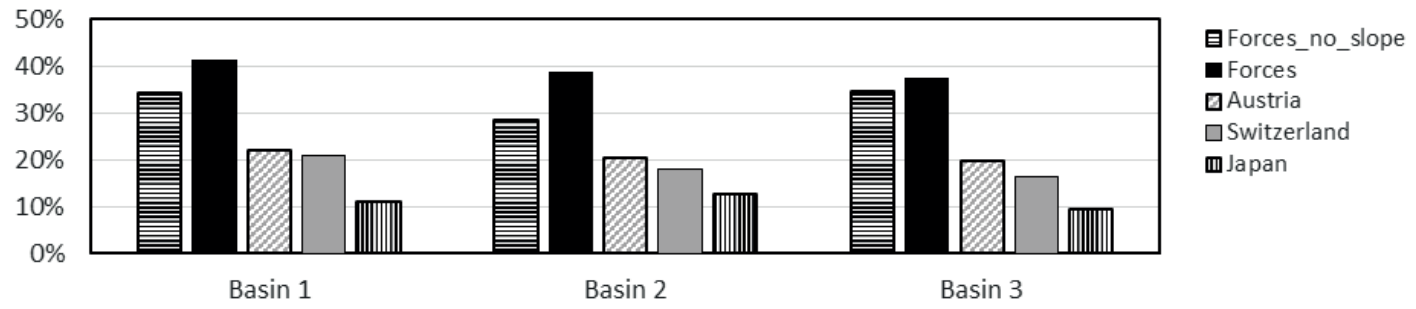

Fig. 6 Percentage of flood prone area affected by high hazard level (red zone).

$U-h$ couples are mostly located in the lower part of the plane (Fig. 7) where the different functions look similar. The greater extension of the high hazard zone estimated by the Austrian method, relative to the Swiss map, is mainly due to the role of the upper depth limit. 


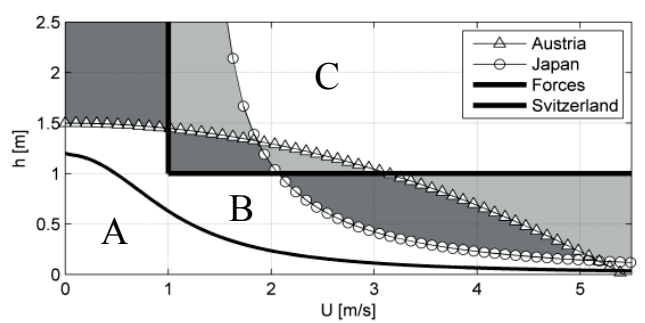

Fig. 7 Comparison of the presented methodologies with reference to the case studies.

The comparison of the maps (Figs 5 and 6) and of the thresholds (Fig. 7) shows that the model suggested in this paper is the most precautionary, even when the slope effect is disregarded. Figure 7 shows the area where all the methodologies assign the maximum hazard level $(\mathbf{C})$ rather than the lowest (A). The shaded areas within the polygons are the zones where hazard levels depend on the used criterion. Finally, zone B is considered the most hazardous class by the stability model only, while the other criteria would assign it to the low hazard area.

The main limit of the Swiss rule is the absence of depth thresholds when the velocities are lower than $1 \mathrm{~m} / \mathrm{s}$, and of the velocity when the deposits are shallower than $1 \mathrm{~m}$. Similarly, the Japanese rule does not provide a depth limit for velocities lower than $1.5 \mathrm{~m} / \mathrm{s}$. In contrast, the Austrian method suggests maximum values both for velocity (about $5.5 \mathrm{~m} / \mathrm{s}$ ) and depth $(1.5 \mathrm{~m})$. In spite of several simplifications, the conceptual model allows assessment of the general features of the process, moving from a simple physical base. Due to the generality of the assumptions, it may be applied to river floods too. In particular, the scheme allows the taking into account the density and the local slope, whose role was studied by Russo et al. (2013). Figure 6 shows that the effect of slope may increase the high hazard areas by up to $10 \%$.

Acknowledgements This work was developed within the Project KULTURisk EU FP7 (Grant agreement no 265280).

\section{REFERENCES}

Arattano, M., Franzi, L. and Marchi, L. (2006) Influence of rheology on debris flow simulation. NHESS 6, $519-528$.

Armanini, A., Fraccarollo, L. and Rosatti, G. (2009) Two-dimensional simulation of debris flows in erodible channels, Computers \& Geosciences 35, 993-1006.

Boniello, M. A., et al. (2010) Rheological investigation and simulation of a debris flow event in Fella watershed. Natural Hazards and Earth System Sciences 10,989-997.

BWW, BRP, BUWAL (2008) Recommendations - Consideration of Flood Hazard for Activities with Spatial Impact.

Cussot, P., et al. (1998) Direct determination of rheological characteristics of debris flow. Journal of Hydraulic Engineering 128, $865-868$

Faber, R. (2006) Flood risk analysis: residual risks and uncertainties in an Austrian context. PhD Dissertation, Universitat fur Bodenkultur, Vienna.

Jonkman, S. N. and Penning-Rowsell, E. (2008) Human instability in flood flows. Journal of the American Water Resources Association 44(5), 1208-1218.

Iverson, R. M. (2003) The debris-flow rheology myth. In: Debris-flow Hazards Mitigation: Mechanics, Prediction and Assessment, v. 1 (ed. D. Rickenmann and C. L. Chen), 303-314. Millpress, Rotterdam.

Mazzoleni, M., et al. (2013) Flooding hazard mapping in floodplain areas affected by piping breaches in the Po River, Italy. Journal of Hydrological Engineering 19(4), 717-731.

Mizuno, H. and Terada, H. (2004) Application to past debris disaster of a method of setting the range of debris flow damage to houses. Interpraevent Symposium, Riva (Tn).

O'Brien, J. S. and Julien, P. (1988) Laboratory analysis of mudflow properties, Journal of Hydraulic Engineering 114(8), $877-887$.

O'Brien, J. S., Julien, P. and Fullerton, W. T. (1993) Two-dimensional water flood and mudflow simulation. Journal of Hydraulic Engineering 119(2), 244-259.

Quan Luna, B., et al. (2012) The application of numerical debris flow modelling for the generation of physical vulnerability curves. NHESS 11, 2047-2060.

Russo, B., Macchione, F. and Gómez, M. (2013). Pedestrian hazard criteria for flooded urban areas. Nat. Hazards 69(1), 251265.

Takahashi, S., Endoh, K. and Muro, Z. I. (1992). Experimental study on people's safety against overtopping waves on breakwaters, Report on the Port and Harbour Institute, 34 (4), 4-31 (in Japanese).

Uchida, T., et al. (2009) Countermeasures for sediment-related disasters in Japan using hazard maps. International Journal of Erosion Control Engineering 2(2), 46-53. 